03,04

\title{
Влияние электронного облучения на диэлектрические характеристики монокристаллов $\mathrm{AgGaSe}_{2}$
}

\author{
(C) А.У. ШелеГ, В.Г. Гуртовой \\ ГО „НПЦ НАН Беларуси по материаловедению“ \\ Минск, Беларусь \\ E-mail: hurtavy@physics.by \\ Поступила в Редакцию 24 апреля 2019 г. \\ В окончательной редакции 24 апреля 2019 г. \\ Принята к публикации 26 апреля 2019 г.
}

\begin{abstract}
Исследовано влияние различных доз электронного облучения на диэлектрическую проницаемость и удельную электропроводность тройных нелинейно-оптических кристаллов $\mathrm{AgGaSe}_{2}$ на различных частотах измерительного поля в интервале температур 100-300 К. Обнаружено, что облучение монокристаллов приводит к уменьшению значений диэлектрической проницаемости и значительному возрастанию электропроводности. Показано, что с ростом температуры диэлектрическая проницаемость и электропроводность увеличиваются. Установлено, что для кристаллов $\mathrm{AgGaSe}_{2}$ характерно наличие нескольких типов проводимости. Обнаружена существенная частотная дисперсия диэлектрических свойств исследованных кристаллов.
\end{abstract}

Ключевые слова: нелинейно-оптические кристаллы, диэлектрическая проницаемость, удельная электропроводность, температурная зависимость, дисперсия, электронное облучение.

DOI: 10.21883/FTT.2019.10.48243.467

\section{1. Введение}

Тройные серебросодержащие соединения $\mathrm{AgGaSe}_{2}$ являются оптически-нелинейными материалами. Для них характерны высокие показатели нелинейности, широкая область прозрачности в видимой и средней инфракрасной области спектра. От широко использующихся в настоящее время материалов они отличаются высокой лучевой стойкостью. Соединение $\mathrm{AgGaSe}_{2}$ относится к прямозонным полупроводникам, имеет структуру халькопирита и кристаллизуется в тетрагональной симметрии с пространственной группой $I 42 d$ и параметрами элементарной ячейки $a=5.757 \AA, c=10.305 \AA[1]$.

Соединения на основе $\mathrm{AgGaSe}_{2}$ и его твердых растворов используются для создания фотопреобразователей солнечной энергии, оптических параметрических осцилляторов, твердотельных источников спинполяризованных электронов и других приборов полупроводниковой оптоэлектроники [2,3]. В последние годы достигнут значительный прогресс в применении монокристаллов прямозонных соединений $\mathrm{AgGaSe}_{2}$ для получения второй и третьей гармоник лазеров на $\mathrm{CO}_{2}$. На основе высококачественных монокристаллов $\mathrm{AgGaSe}_{2}$ разрабатываются детекторы рентгеновского и гамма-излучения, работающие при комнатной температуре. Однако, несмотря на определенные успехи, достигнутые в изучении физических свойств соединения $\mathrm{AgGaSe}_{2}$, многие физические характеристики данных кристаллов остаются пока неисследованными или требуют дальнейшего уточнения.

Целью данной работы было изучение влияния различных доз электронного облучения на температур- ные зависимости диэлектрической проницаемости $(\varepsilon)$ и удельной проводимости $(\sigma)$ монокристаллов $\mathrm{AgGaSe}_{2}$ в широком интервале температур.

\section{2. Методика эксперимента}

Измерения диэлектрической проницаемости и электропроводности проводились методом плоского конденсатора на монокристаллических пластинках с помощью цифрового измерителя E7-20 на частотах измерительного поля $10^{3}-10^{6} \mathrm{~Hz}$ в температурном диапазоне $100-300 \mathrm{~K}$. Образцы представляли собой монокристаллические пластинки $\mathrm{AgGaSe}_{2}$ размерами $\sim 7 \times 5 \times 1 \mathrm{~mm}$. Поверхности пластинок совпадали с кристаллографической плоскостью (011). На образцы наносились омические серебряные контакты, затем образцы помещались между металлическими прижимными контактами. Держатель с образцом экранировался латунным стаканом, на который через изоляционную прослойку из слюды намотан нагреватель. Питание нагревателя осуществлялось постоянным током от стабилизированного источника. Температура контролировалась при помощи дифференциальной хромель-копелевой термопары и универсального цифрового вольтметра. Измерения велись методом непрерывного квазистатического нагревания со скоростью $\sim 0.5 \mathrm{~K} / \mathrm{min}$. Точность измерения температуры составляла $0.1-0.2 \mathrm{~K}$. Погрешность измерений диэлектрических характеристик составляла $\sim 0.5 \%$. Значения диэлектрической проницаемости и удельной электропроводности рассчитывались по формуле, соответствующей плоскопараллельному конденсатору. 
Проводились исследования как необлученных образцов, так и облученных электронами с энергией $4 \mathrm{MeV}$ дозами $10^{15}$ и $10^{16} \mathrm{~cm}^{-2}$.

\section{3. Результаты исследований}

На рис. 1 представлены температурные зависимости диэлектрической проницаемости монокристалла $\mathrm{AgGaSe}_{2}$, полученные на различных частотах измерительного поля. Как видно из рисунка, значения $\varepsilon$ с ростом температуры увеличиваются. Наблюдается значительная дисперсия диэлектрической проницаемости. C ростом частоты значения $\varepsilon$ уменьшаются, что обусловлено, как известно, релаксационными процессами, происходящими в высокочастотной области измерений.

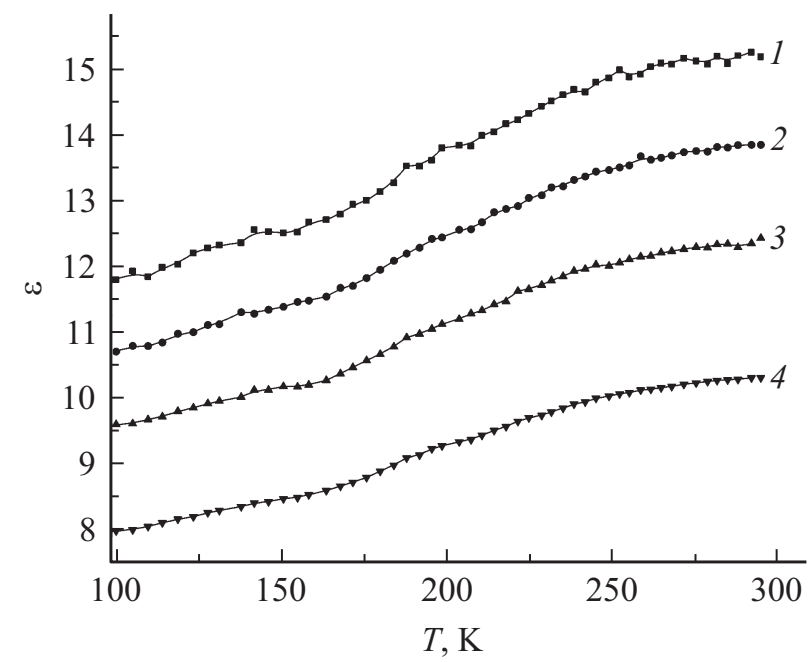

Pис. 1. Температурные зависимости диэлектрической проницаемости монокристалла $\mathrm{AgGaSe}_{2}$ на частотах: $1-10^{3} \mathrm{~Hz}$; $2-10^{4} \mathrm{~Hz} ; 3-10^{5} \mathrm{~Hz} ; 4-10^{6} \mathrm{~Hz}$.

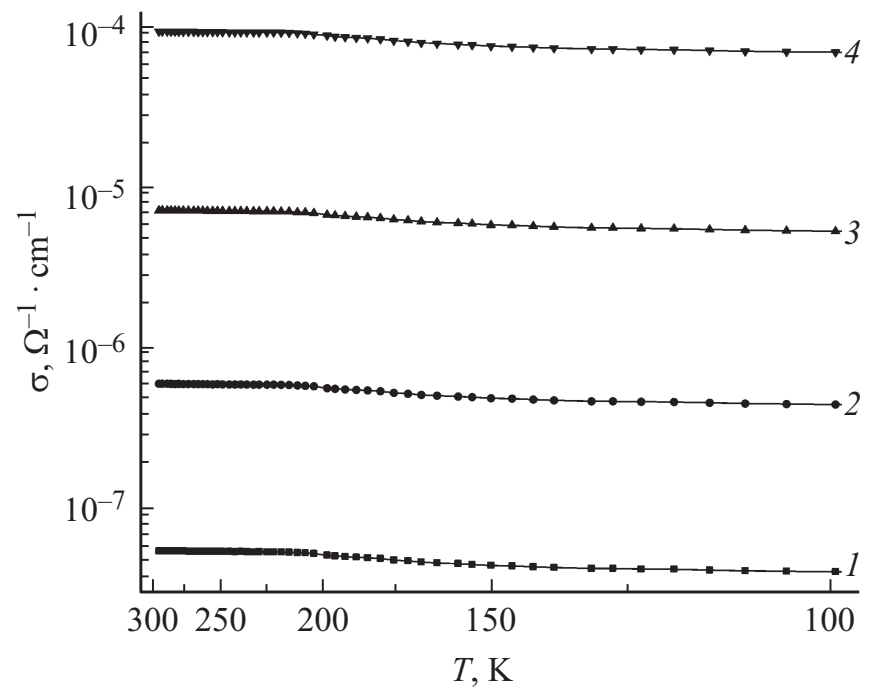

Pис. 2. Температурные зависимости удельной электропроводности монокристалла $\mathrm{AgGaSe}_{2}$ на частотах: $1-103 \mathrm{~Hz} ; 2-$ $10^{4} \mathrm{~Hz} ; 3-10^{5} \mathrm{~Hz} ; 4-10^{6} \mathrm{~Hz}$.

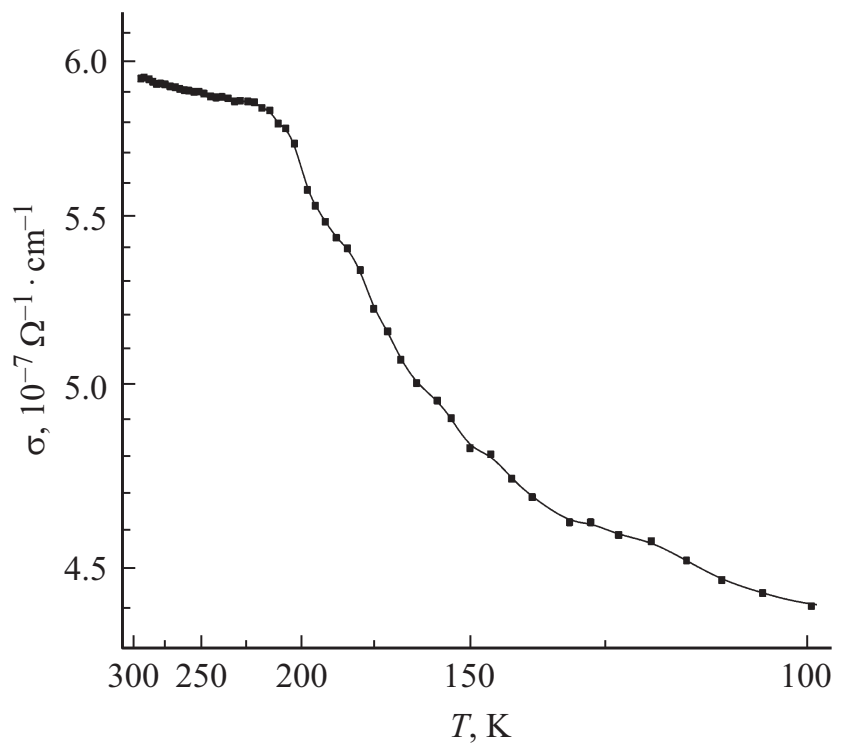

Рис. 3. Температурная зависимость удельной электропроводности $\mathrm{AgGaSe}_{2}$ на частоте $10^{5} \mathrm{~Hz}$.

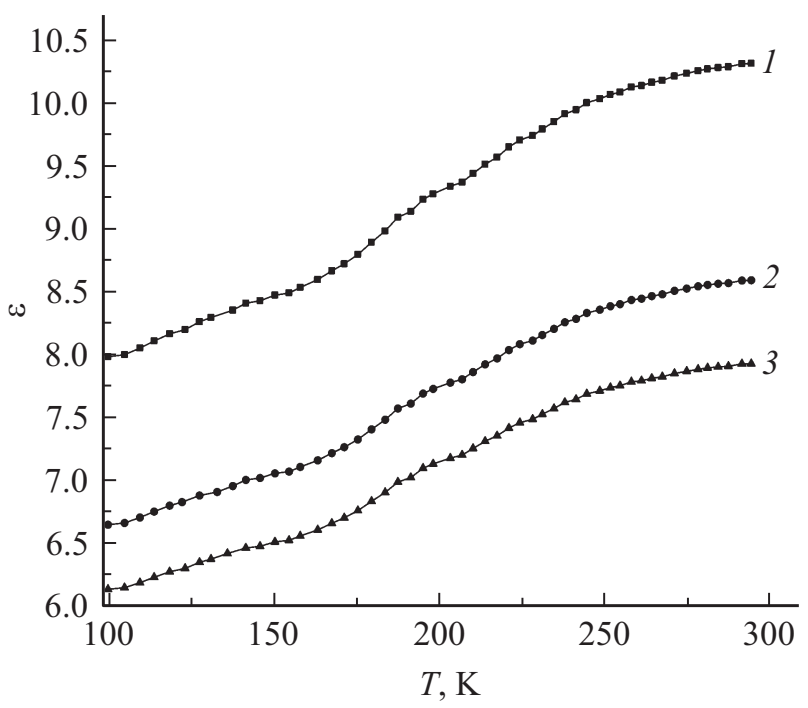

Рис. 4. Температурные зависимости диэлектрической проницаемости монокристалла $\mathrm{AgGaSe}_{2}$ на частоте $10^{6} \mathrm{~Hz}$ для различных доз электронного облучения: 1 - необлученный; $2-10^{15} \mathrm{~cm}^{-2} ; 3-10^{16} \mathrm{~cm}^{-2}$.

На рис. 2 представлены температурные зависимости удельной электропроводности монокристалла $\mathrm{AgGaSe}_{2}$ на различных частотах. На рис. 3 изображена кривая зависимости проводимости от температуры на частоте измерительного поля $10 \mathrm{kHz}$. Из рисунков видно, что значения $\sigma$ увеличиваются с ростом температуры, что обусловлено ростом концентрации свободных носителей заряда (проявление полупроводниковых свойств). Участки с разным наклоном на кривых $\sigma=f(T)$ указывают на сложный механизм переноса заряда и наличие нескольких типов проводимости в этих кристаллах. 


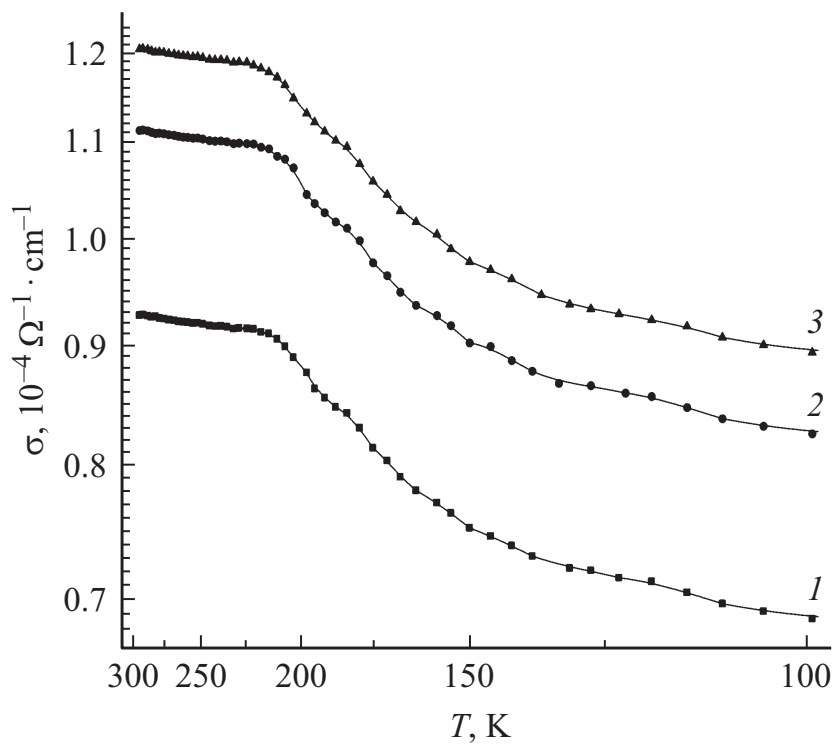

Рис. 5. Температурные зависимости удельной электропроводности монокристалла $\mathrm{AgGaSe} 2$ на частоте $10^{6} \mathrm{~Hz}$ для различных доз электронного облучения: 1 - необлученный; 2 $10^{15} \mathrm{~cm}^{-2} ; 3-10^{16} \mathrm{~cm}^{-2}$.



Рис. 6. Зависимости диэлектрических характеристик $\mathrm{AgGaSe}_{2}$ от дозы электронного облучения на частоте $10^{6} \mathrm{~Hz}$ при температуре $300 \mathrm{~K}: 1$ - диэлектрическая проницаемость; 2 удельная электропроводность.

Следует отметить, что у кристалла $\mathrm{AgGaSe}_{2}$ наблюдается значительная дисперсия электропроводности. Значения проводимости в изученном интервале частот $\left(10^{3} \mathrm{~Hz}-10^{6} \mathrm{~Hz}\right)$ изменяются более чем на три порядка. С ростом частоты измерительного поля значения $\sigma$ сильно увеличиваются, что обусловлено релаксационными процессами, происходящими в высокочастотной области измерений.

На рис. 4 и 5 приведены температурные зависимости диэлектрической проницаемости и проводимости монокристалла $\mathrm{AgGaSe}_{2}$ для различных доз облучения на частоте измерительного поля $10^{6} \mathrm{~Hz}$. Температурные зависимости для других частот выглядят аналогично. На рис. 6 показаны зависимости диэлектрических характеристик $\mathrm{AgGaSe}_{2}$ от дозы электронного облучения на частоте $10^{6} \mathrm{~Hz}$ при температуре $300 \mathrm{~K}$.

Из рисунков видно, что облучение монокристаллов пучком электронов приводит к уменьшению значений диэлектрической проницаемости и значительному возрастанию электропроводности во всей исследованной области температур. Такое поведение значений $\varepsilon$ под воздействием облучения электронами может быть вызвано радиационно стимулированным старением образцов, связанным с активизацией процесса миграции естественных дефектов под влиянием облучения, приводящим к снижению значений $\varepsilon$. Причиной роста значений электропроводности $\sigma$ монокристаллов соединений $\mathrm{AgGaSe}_{2}$ является, скорее всего, увеличение концентрации дефектов и, как следствие, возрастания вклада примесной проводимости.

\section{4. Заключение}

Проведены исследования влияния температуры на диэлектрическую проницаемость и электропроводность монокристаллов $\mathrm{AgGaSe}_{2}$ на различных частотах измерительного поля в области температур $100-300 \mathrm{~K}$. Показано, что с ростом температуры диэлектрическая проницаемость и электропроводность увеличиваются.

Установлено, что для кристаллов $\mathrm{AgGaSe}_{2}$ характерно наличие нескольких типов проводимости. Обнаружена существенная частотная дисперсия электропроводности и диэлектрических свойств исследованных кристаллов.

Исследовано влияние электронного облучения на электрические свойства монокристаллов $\mathrm{AgGaSe}_{2}$. Установлено, что увеличение дозы облучения приводит к уменьшению диэлектрической проницаемости и значительному возрастанию электропроводности во всей исследованной области температур.

\section{Финансирование работы}

Исследования проведены при поддержке Белорусского Фонда фундаментальных исследований (договор № Ф18УКА-002).

\section{Конфликт интересов}

Авторы заявляют, что у них нет конфликта интересов.

\section{Список литературы}

[1] B. Tell, H.M. Kasper. Phys. Rev. B 4, 12, 4455 (1971).

[2] Y. Cui, U.N. Roy, A. Burger, J.T. Goldstein. J. Appl. Phys. 103, 12, 123514-1 (2008).

[3] H.-W. Wang, M.-h. Lu. Opt. Commun. 192, 3, 357 (2001).

Редактор К.В. Емщев 